\title{
Effective utilization of waste ash from MSW and coal co-combustion power plant-Zeolite synthesis
}

\author{
Yun Fan ${ }^{\mathrm{a}, \mathrm{b}}$, Fu-Shen Zhang ${ }^{\mathrm{a}, *}$, Jianxin Zhu ${ }^{\mathrm{a}}$, Zhengang Liu ${ }^{\mathrm{a}, \mathrm{b}}$ \\ ${ }^{a}$ Research Center for Eco-Environmental Sciences, Chinese Academy of Sciences, 18 Shuangqing Road, Beijing 100085, China \\ ${ }^{\mathrm{b}}$ Graduate University of Chinese Academy of Sciences, Beijing 100039, China \\ Received 13 May 2007; received in revised form 27 July 2007; accepted 23 August 2007 \\ Available online 30 August 2007
}

\begin{abstract}
The solid by-product from power plant fueled with municipal solid waste and coal was used as a raw material to synthesize zeolite by fusionhydrothermal process in order to effectively use this type of waste material. The effects of treatment conditions, including $\mathrm{NaOH} / \mathrm{ash}$ ratio, operating temperature and hydrothermal reaction time, were investigated, and the product was applied to simulated wastewater treatment. The optimal conditions for zeolite $\mathrm{X}$ synthesis were: $\mathrm{NaOH} / \mathrm{ash}$ ratio $=1.2: 1$, fusion temperature $=550{ }^{\circ} \mathrm{C}$, crystallization time $=6-10 \mathrm{~h}$ and $\mathrm{crystallization}$ temperature $=90^{\circ} \mathrm{C}$. In the synthesis process, it was found that zeolite $\mathrm{X}$ tended to transform into zeolite $\mathrm{HS}$ when NaOH/ash ratio was 1.8 or higher, crystallization time was $14-18 \mathrm{~h}$, operating temperature was $130^{\circ} \mathrm{C}$ or higher. The $\mathrm{CEC}$ value, BET surface area and pore volume for the synthesized product at optimal conditions were $250 \mathrm{cmol} \mathrm{kg}{ }^{-1}, 249 \mathrm{~m}^{2} \mathrm{~g}^{-1}$ and $0.46 \mathrm{~cm}^{3} \mathrm{~g}^{-1}$ respectively, higher than coal fly ash based zeolite. Furthermore, when applied to $\mathrm{Zn}^{2+}$ contaminated wastewater treatment, the synthesized product presented larger adsorption capacity and bond energy than coal fly ash based zeolite, and the adsorption isotherm data could be well described by Langmuir and Freundlich isotherm models. These results demonstrated that the special type of co-combustion ash from power plant is suitable for synthesizing high quality zeolite, and the products are suitable for heavy metal removal from wastewater.
\end{abstract}

(C) 2007 Elsevier B.V. All rights reserved.

Keywords: Municipal solid waste; Co-combustion ash; Zeolite; Wastewater; Heavy metal

\section{Introduction}

Co-combustion of municipal solid waste (MSW) with coal for electricity generation is a unique MSW disposal way, which is carried out in China. Every year, more than 170 million tons of MSW is generated in urban areas of China and the amount increases at 8-9wt.\% yearly [1]. Currently, there are three main ways to dispose the MSW, i.e., landfill, composting and incineration. Among them, incineration is becoming more and more attractive for its advantages of significantly reducing the waste volume (about 90\%), mass (about 70\%), toxicity and energy recovery. However, MSW incineration ash usually contains high levels of various heavy metals and salts, and serious environmental problems may occur if the waste is not treated properly before final disposal. In recent years, generating power with MSW has

\footnotetext{
* Corresponding author. Tel.: +86 1062849515 ; fax: +86 1062849515 .

E-mail address: fszhang @ rcees.ac.cn (F.-S. Zhang).
}

been greatly encouraged by the government, and more than 50 power plants fueled with MSW and coal are running in the whole country. MSW, in China, is generally collected without separating into burnable and unburnable matters, thus is made up of different organic and inorganic fractions such as paper, plastic, glass, metal, fabric, kitchen residue, wood, stone, etc. This type of waste has the general properties of low heat value (approx. $4200 \mathrm{~kJ} \mathrm{~kg}^{-1}$ ) and high water content, thus needs coal addition for effective combustion in the power plants. The government usually provides the coal freely for use in the power plants.

Recently, there are some reports about co-combustion MSW with coal focusing on the purification of the discharged gas and characterization of heavy metal in the ash. Gullett et al. reported that co-combustion of the waste with coal could suppress polychlorinated dibenzodioxins/polychlorinated dibenzofurans (PCDDs/PCDFs) formation [2]. Meanwhile, by using fluidized absorption tower and fabric filter, dioxins content in the flue gas could be reduced to as low as $0.1573 \mathrm{ng}\left(\mathrm{N} \mathrm{m}^{3}\right)^{-1}$, which approaches the emission standard of the developed country 
[3]. In the combustion process, the conversion rate of $\mathrm{Cl}$ to $\mathrm{HCl}$ increased with temperature, and the concentration of $\mathrm{NO}$ decreased with the increasing of $\mathrm{HCl}$ concentration, because that the addition of $\mathrm{HCl}$ consuming the radical pool of $\mathrm{H}$, $\mathrm{OH}$, and $\mathrm{O}$ leads to $\mathrm{HCl}$ inhibiting the oxidation of $\mathrm{HCN}$ and NCO to form NO [4]. The leaching amounts of heavy metals from the resulting ash, such as $\mathrm{As}, \mathrm{Zn}, \mathrm{Cr}, \mathrm{Cd}$ etc., surpassed the limited values for hazardous wastes regulated by China EPA [5], implying that the ash has potential risk to the environment. Furthermore, there are also some reports about optimizing incinerator systems. For example, Bao et al. reported that increasing the quantity of blending coal could shorten the pyrolysis time and increase the heating value of the gaseous product in pyrolyzing incinerators [6]. Nevertheless, little information is available on the disposal and effective utilization of the vast amount of co-combustion ash. The ash from co-combustion of MSW with coal is mainly made of $\mathrm{SiO}_{2}-\mathrm{Al}_{2} \mathrm{O}_{3}-\mathrm{CaO}-\mathrm{Fe}_{2} \mathrm{O}_{3}$ [7], presenting a similar composition of natural zeolite, which makes it possible to convert the ash into a zeolite-like material.

Many different types of zeolites have been synthesized from various waste ashes such as coal fly ash and MSW incineration ash using hydrothermal or fusion methods [8-10]. Zeolites possess the properties of ion exchange, selective adsorption and can be used as molecular sieves. These types of zeolites have been widely used for environment remediation and for different industrial applications such as removal of heavy metals and arsenate from wastewater [11], flue gas [12] and radioactive waste [13], etc. For example, Scott et al. successfully synthesized zeolite $\mathrm{X}$ and zeolite Na-P1 from two different types of fly ashes, and demonstrated that the products were quite effective for lead ion removal from aqueous system [14]. In addition, zeolites have also been used as catalysts for various purposes [15]. However, to our best knowledge, no information is available on the transformation of the special type of waste ash from MSW and coal fueled power plant into zeolite.

The objectives of this research were to examine the possibility and provide preliminary information of converting MSW and coal co-combustion ash into zeolite. The optimum synthesis conditions were established, and the physical and chemical properties of the synthesized products were determined. The ultimate goal was to develop a new way to utilize the abundant waste ash.

\section{Experimental}

\subsection{Materials}

Waste ash (abbreviated as MSWCA) employed in this study was provided by a power plant fueled with MSW and coal located in northern China. The plant has two $24 \mathrm{~h}$-run fluidizedbed incinerators with MSW disposal ability of 1000 tons per day. The electricity generation ability of this power plant is $36,000 \mathrm{~kW} \mathrm{~h}^{-1}$. To compare the properties of the product developed in this study with zeolite synthesized from traditional coal fly ash (CFA), CFA sample was also collected from a power plant fueled with the same type of coal as used in the MSW and coal power plant. The raw ash was screened through an 80mesh sieve, dried at $105^{\circ} \mathrm{C}$ for $24 \mathrm{~h}$ and stored in a desiccator for use.

\subsection{Methods}

\subsubsection{Zeolite synthesis}

Fusion technique combined with hydrothermal treatment was performed for the zeolite synthesis based on the study of Molina and Poole [9]. Specifically, $5 \mathrm{~g}$ waste ash was mixed and ground with $\mathrm{NaOH}$ powder to obtain a homogeneous mixture, then heated in a nickel crucible at $550^{\circ} \mathrm{C}$ for $1 \mathrm{~h}$. Different $\mathrm{NaOH} /$ ash ratios $\left(0.6,0.8,1,1.2,1.4,1.6,1.8\right.$ and $\left.2.0\left(\mathrm{~g} \mathrm{~g}^{-1}\right)\right)$ were tested. The fusion products were then ground and dissolved in $45 \mathrm{~mL}$ distilled water, and the mixtures were transferred into $100 \mathrm{~mL}$ reaction bombs followed by an aging process with vigorous shaking at room temperature for $24 \mathrm{~h}$. The mixtures were then crystallized under static conditions at different temperatures $\left(40,60,80,90,110,130,150\right.$ and $\left.180^{\circ} \mathrm{C}\right)$ for different times $(0.5,2,4,6,8,10,14,18,22$ and $26 \mathrm{~h})$. The solids were recovered by vacuum filtration, washed for several times with distilled water until the solution reached $\mathrm{pH} 10$ and dried overnight at $105^{\circ} \mathrm{C}$. Some of the zeolitization experiments were randomly duplicated in order to study the process repeatability.

\subsubsection{Cation exchange capacity (CEC) determination}

CEC values of the synthesized products were determined using US EPA SW-846 Method 9081. Specifically, $4 \mathrm{~g}$ of the sample was mixed with $33 \mathrm{~mL}$ of $1.0 \mathrm{~mol} \mathrm{~L}^{-1}$ sodium-acetate solution, and the mixture was shaken in a mechanical shaker for $5 \mathrm{~min}$ and centrifuged. The supernatant liquid was decanted and the residue was treated again with fresh sodium-acetate solution. Subsequently, the residue was washed three times with $33 \mathrm{~mL}$ ethanol. An ammonium-acetate solution was then added to replace the absorbed sodium with ammonium. The supernatant was collected and diluted to $100 \mathrm{~mL}$ with ammonium-acetate solution and the sodium concentration was determined by inductively coupled plasma optical emission spectrometry (ICP-OES) (PerkinElme OPTIMA 2000, USA)

\subsubsection{X-ray diffraction analysis}

The crystalline properties of the raw material and the synthesized products were examined by X-ray diffraction (XRD) (Philips PW 1700, Holand) using $\mathrm{CuK} \alpha$ radiation at $45 \mathrm{kV}$ and $250 \mathrm{~mA}$, and a scanning rate of $2 \%$ min from 10 to $70^{\circ}$ was performed. A software namely Joint Committee of Powder Diffraction Standards (JCPDS) was used to identify the crystalline phases.

\subsubsection{XRF, SEM and BET surface area analysis}

Chemical composition of the raw ash was determined by X-ray fluorescence (XRF) (Philips PW 2404, Holand). The morphological properties of the raw ash and synthesized products were examined by scanning electron microscope (SEM) 
Table 1

Chemical compositions of the raw ash employed in this study

\begin{tabular}{lr}
\hline Component & wt. $\%$ \\
\hline $\mathrm{SiO}_{2}$ & 45.50 \\
$\mathrm{Al}_{2} \mathrm{O}_{3}$ & 22.60 \\
$\mathrm{CaO}$ & 6.29 \\
$\mathrm{Fe}_{2} \mathrm{O}_{3}$ & 3.45 \\
$\mathrm{SO}_{3}$ & 2.34 \\
$\mathrm{~K}_{2} \mathrm{O}$ & 1.41 \\
$\mathrm{TiO}_{2}$ & 1.05 \\
$\mathrm{MgO}_{2}$ & 0.72 \\
$\mathrm{P}_{2} \mathrm{O}_{5}$ & 0.41 \\
$\mathrm{MnO}$ & 0.05 \\
$\mathrm{Na}_{2} \mathrm{O}$ & 0.02 \\
$\mathrm{LOI}^{\mathrm{a}}$ & 11.60 \\
\hline
\end{tabular}

${ }^{\text {a }}$ Loss on ignition at $600^{\circ} \mathrm{C}$ for $3 \mathrm{~h}$.

(Hitachi S-3000N, Japan), and the surface area and pore volume were determined from $\mathrm{N}_{2}$ gas adsorption and desorption isotherms measured at $-196^{\circ} \mathrm{C}$ using a surface analyzer from Micromeritics company (ASAP2000, USA).

\subsubsection{Adsorption isotherms}

For batch adsorption experiments, stock solution containing $1000 \mathrm{mg} \mathrm{L}^{-1}$ of $\mathrm{Zn}^{2+}$ was prepared by dissolving $4.55 \mathrm{~g}$ $\mathrm{ZnNO}_{3} \cdot 6 \mathrm{H}_{2} \mathrm{O}$ (analytical grade) in $1 \mathrm{~L}$ doubly distilled water. In the adsorption process, sub-solutions with $\mathrm{Zn}^{2+}$ concentration ranging from 50 to $200 \mathrm{mg} \mathrm{L}^{-1}$ was prepared by diluting appropriate amount of the stock solution. A certain amount of the product, synthesized at optimum conditions, was added with $50 \mathrm{~mL}$ of the $\mathrm{Zn}^{2+}$ solutions in a series of stopper bottles. The suspensions, with duplicate, were then placed in an isothermal shaker $\left(30 \pm 1{ }^{\circ} \mathrm{C}\right)$ for a fixed period of time to allow complete equilibration. Samples of the equilibrated solutions were filtered and analyzed using ICP-OES for $\mathrm{Zn}^{2+}$ concentration determination.

\section{Results and discussion}

\subsection{Waste ash characterization}

The chemical composition of the raw ash is shown in Table 1. The $\mathrm{SiO}_{2} / \mathrm{Al}_{2} \mathrm{O}_{3}$ ratio of the ash is about 2.0, indicating that this type of ash is favorable for use as a raw material for low Si zeolite synthesis [16]. Furthermore, the ash also has lower $\mathrm{Fe}$ and $\mathrm{Ca}$ content compared to coal fly ash (4-10\% $\left.\mathrm{Fe}_{2} \mathrm{O}_{3}, 5-30 \% \mathrm{CaO}\right)$ [17]. Among them, $\mathrm{Fe}$ associates to the presence of Magnetite, which can behave as an inert material for zeolite synthesis while Ca could act as an inhibitor through the formation of calcium silicate [17].

The XRD pattern of the raw ash (omitted) indicates that the mineralogical phases of the ash are mainly quartz $\left(\mathrm{SiO}_{2}\right)$, Gismondine $\left(\mathrm{CaAl}_{2} \mathrm{Si}_{2} \mathrm{O}_{8} \cdot 4 \mathrm{H}_{2} \mathrm{O}\right)$, Hematite $\left(\mathrm{Fe}_{2} \mathrm{O}_{3}\right)$, and Anorthite $\left([\mathrm{Ca}, \mathrm{Na}][\mathrm{Al}, \mathrm{Si}] \cdot 2 \mathrm{Si}_{2} \mathrm{O}_{8}\right)$. The mullite, which is resistant aluminum-silicate phase, could not be identified. Therefore, the zeolites synthesized from the co-combustion ash are expected to be different from those from traditional coal fly ash.

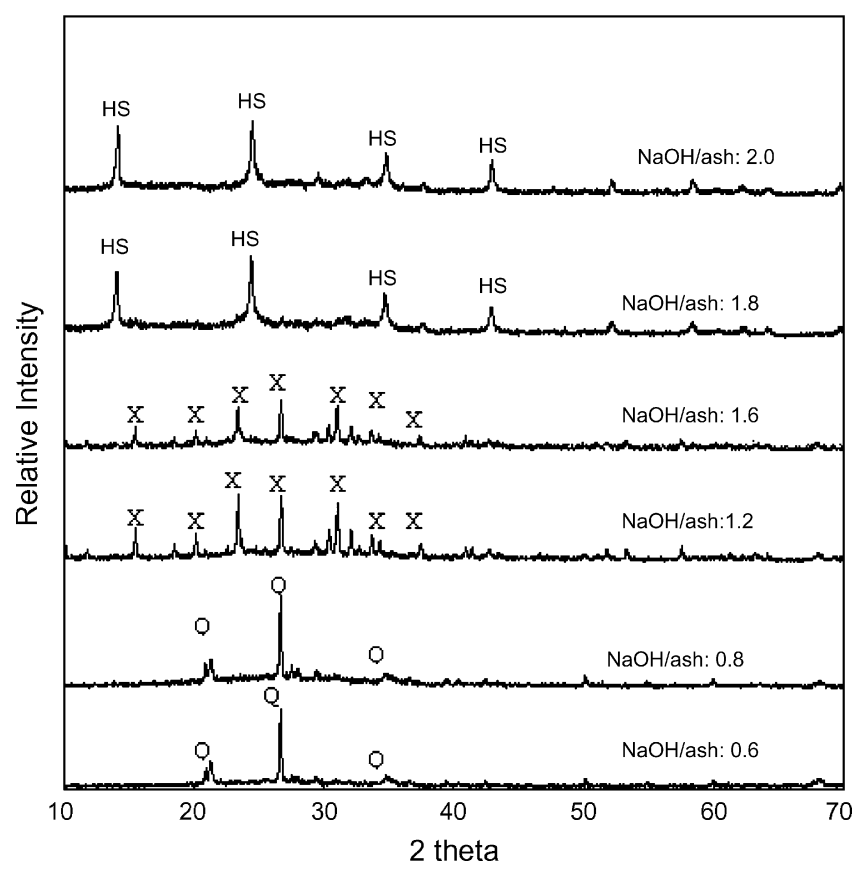

Fig. 1. XRD patterns of the synthesized products at different $\mathrm{NaOH} /$ ash ratios (Q-quartz; X-zeolite X; HS—hydroxysodalite).

\subsection{Zeolite synthesis and characterization}

\subsubsection{Effect of $\mathrm{NaOH} /$ ash ratio}

The effect of $\mathrm{NaOH} /$ ash ratio on zeolite formation was determined by mixing $\mathrm{NaOH}$ with the ash at the ratio range of 0.6 to 2.0 at $90{ }^{\circ} \mathrm{C}$ for $6 \mathrm{~h}$. Fig. 1 shows the XRD spectra of the products obtained at different $\mathrm{NaOH} /$ ash ratios. Zeolites were formed when the $\mathrm{NaOH} / \mathrm{ash}$ ratio increased to 1.2 or higher. Thus, relatively high CEC values were obtained for the synthesized products (Fig. 2). At a $\mathrm{NaOH} /$ ash ratio of 1.2, quartz peaks disappeared and zeolite $\mathrm{X}\left(\mathrm{Na}_{88} \mathrm{Al}_{88} \mathrm{Si}_{104} \mathrm{O}_{384} \cdot 220 \mathrm{H}_{2} \mathrm{O}\right.$, JCPDS 38-0237) peaks appeared. When $\mathrm{NaOH} /$ ash ratio reached 1.8 , zeolite HS $\left(\mathrm{Na}_{1.08} \mathrm{Al}_{2} \mathrm{Si}_{1.68} \mathrm{O}_{7.44} \cdot 1.8 \mathrm{H}_{2} \mathrm{O}\right.$, JCPDS 31-1271) peaks appeared indicating that zeolite $\mathrm{X}$ transformed into zeolite $\mathrm{HS}$. It is well known that $\mathrm{NaOH}$ could dissolve $\mathrm{Si}$ and $\mathrm{Al}$ contained in the ash, and the dissolution is enhanced with the increase of $\mathrm{NaOH} /$ ash ratio. Since the solubility of $\mathrm{Al}_{2} \mathrm{O}_{3}$ into the alkaline solution is lower than that of $\mathrm{SiO}_{2}$, thus a high $\mathrm{NaOH} /$ ash ratio result in a low $\mathrm{SiO}_{2} / \mathrm{Al}_{2} \mathrm{O}_{3}$ ratio, which could improve the formation of zeolite HS, because zeolite HS generally contains higher amount of Al than zeolite X [18].

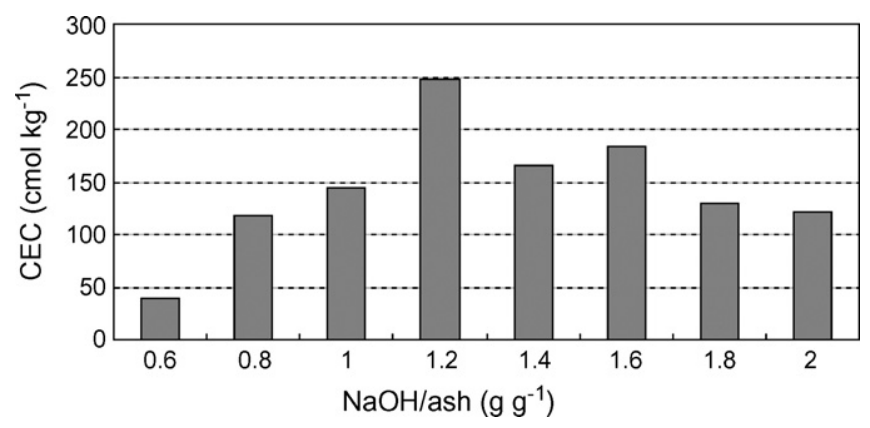

Fig. 2. Effect of $\mathrm{NaOH} / \mathrm{ash}$ ratio on $\mathrm{CEC}$ values of the synthesized products. 


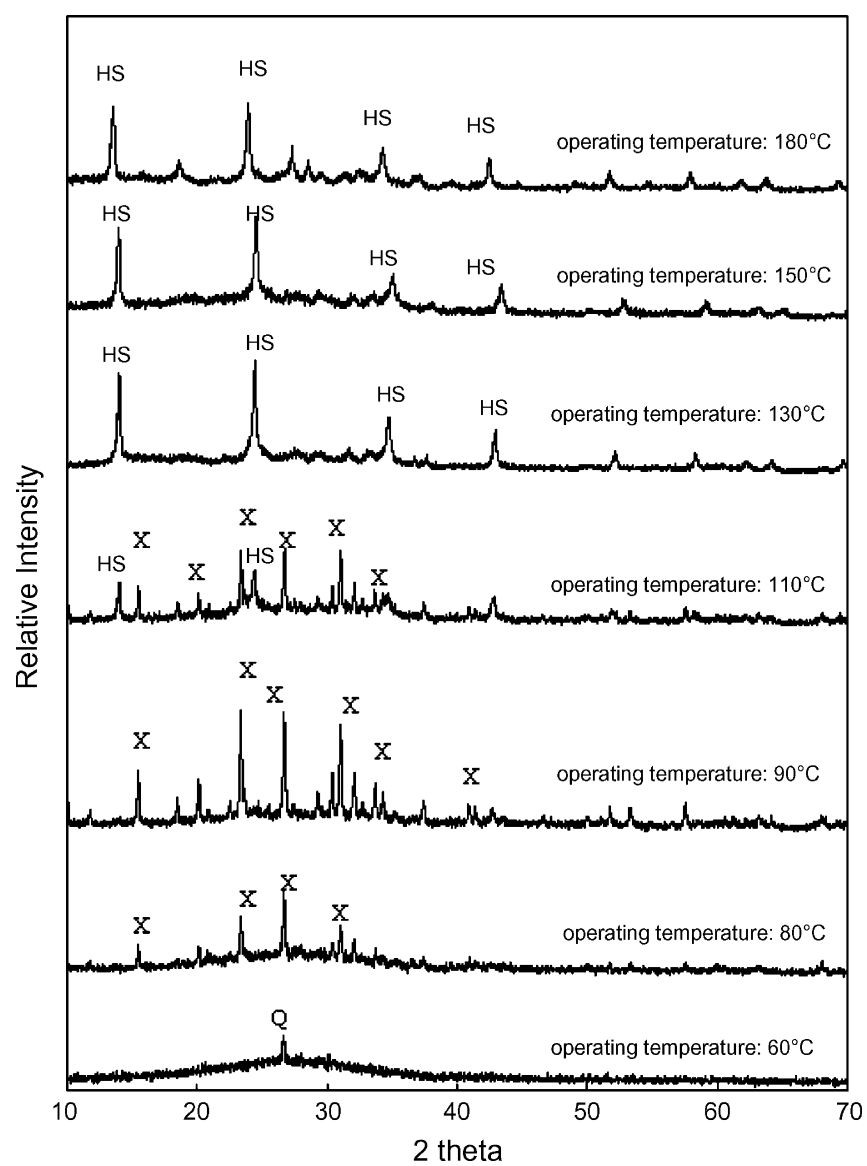

Fig. 3. XRD patterns of the synthesized products at different temperatures. (Q-quartz; X—zeolite X; HS—hydroxysodalite).

On the other hand, $\mathrm{NaOH}$ amount greatly affects the CEC values of the synthesized products (Fig. 2). When the $\mathrm{NaOH} /$ ash ratio was increased to 1.2, a maximum value of CEC $\left(250 \mathrm{cmol} \mathrm{kg}^{-1}\right)$ was obtained which is treble that of the raw ash (CEC $63.7 \mathrm{cmol} \mathrm{kg}^{-1}$ ). The CEC value decreased when zeolite $\mathrm{X}$ changed to zeolite HS, because zeolite $\mathrm{X}$ that belongs to faujasite has a larger pore size and specific surface area than zeolite HS [9]. In general, the CEC values of MSWCA zeolites are similar to that of some commercial zeolites in the range of $200-300 \mathrm{cmol} \mathrm{kg}^{-1}$ [10].

\subsubsection{Effect of operating temperature}

The alumino-silicate fused mass/gel obtained after fusion was amorphous but changed to crystalline state when subjected to hydrothermal treatment. Fig. 3 shows that no zeolite was formed at $60{ }^{\circ} \mathrm{C}$, indicating that conversion of the ash into silicates and aluminates was negligible when the temperature was too low. Zeolitic phase was observed at $80^{\circ} \mathrm{C}$ and a maximum crystallinity at $90^{\circ} \mathrm{C}$ was obtained. At $110^{\circ} \mathrm{C}$, part of the zeolite $\mathrm{X}$ transformed into zeolite HS, coinciding with the decreasing CEC value (Fig. 4). When the temperature reached $130^{\circ} \mathrm{C}$, zeolite $\mathrm{X}$ transformed into zeolite HS entirely.

The effect of operating temperature on CEC is shown in Fig. 4. Compared to the raw ash, CEC values of the treated ash increased from 63.7 to $172 \mathrm{cmol} \mathrm{kg}^{-1}$ at $40^{\circ} \mathrm{C}$, indicating that

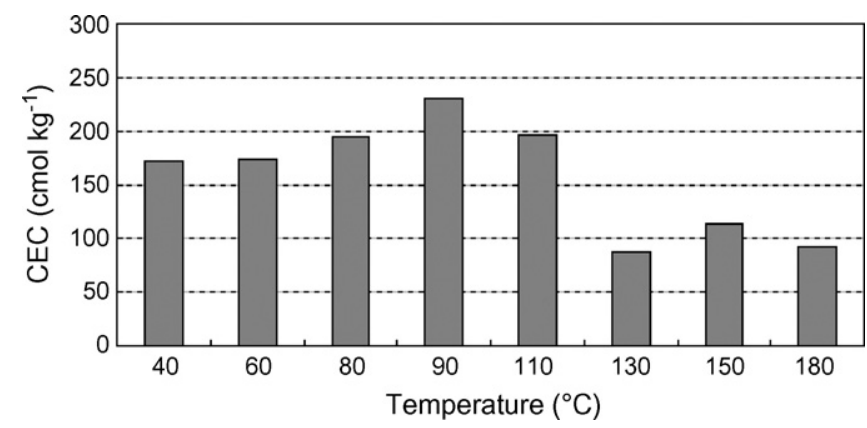

Fig. 4. Effect of temperature on the CEC values of the synthesized products.

the mineralogical properties of the ash changed below $80^{\circ} \mathrm{C}$, though zeolite $\mathrm{X}$ could not be formed at the lower temperature. The CEC value increased to maximum value $\left(250 \mathrm{cmol} \mathrm{kg}^{-1}\right)$ at $90^{\circ} \mathrm{C}$, showing a coincident trend with the crystalline phase change (Fig. 3).

\subsubsection{Effect of hydrothermal reaction time}

Fig. 5 shows the XRD spectra of the products obtained at different reaction time. A reaction time of $6 \mathrm{~h}$ is sufficient for the formation of zeolite X. For the reaction time of $14 \mathrm{~h}$, zeolite X transformed into another phase, i.e. zeolite HS. However, longer time crystallization caused the re-transformation of zeolite HS to zeolite $\mathrm{X}$, and the peaks of zeolite HS disappear completely at around $22 \mathrm{~h}$. Zeolite X exhibited a change of formationdecomposition-reformation along with the crystallization time, which could be explained by the difference of dissolving rate between $\mathrm{Si}$ and $\mathrm{Al}$. In the zeolite synthesis process, the dissolving rate of $\mathrm{Si}$ increased with time at the early stage but

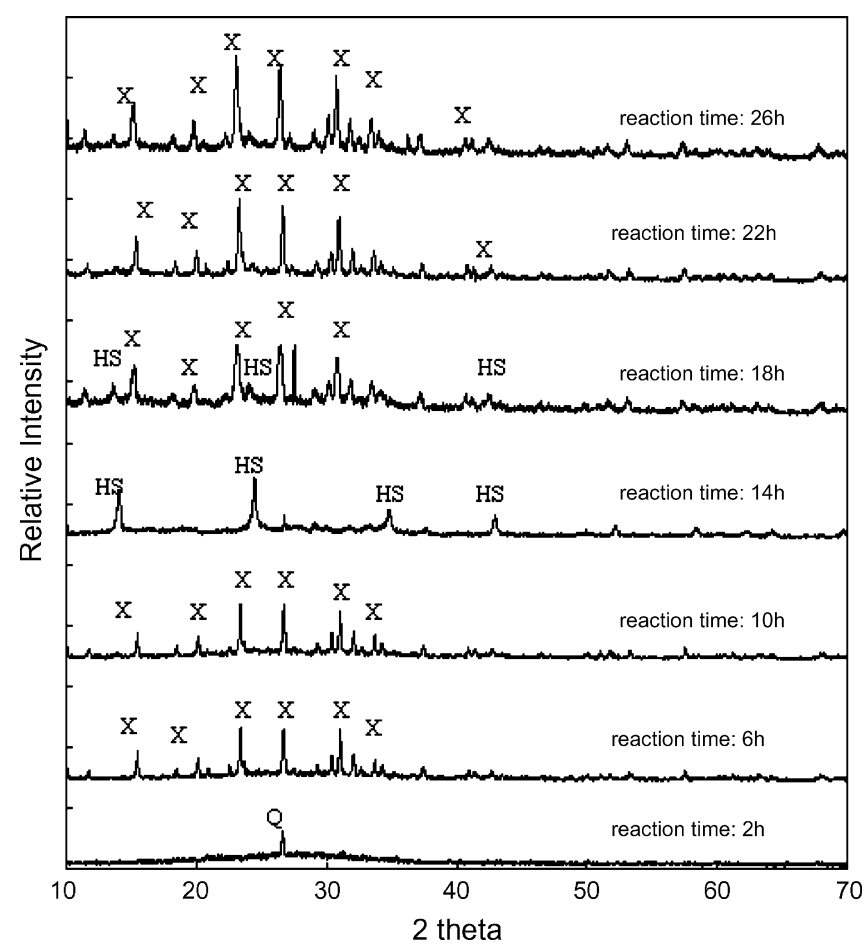

Fig. 5. XRD of the synthesized products at different reaction times. (Q-quartz; X-zeolite X; HS-hydroxysodalite). 


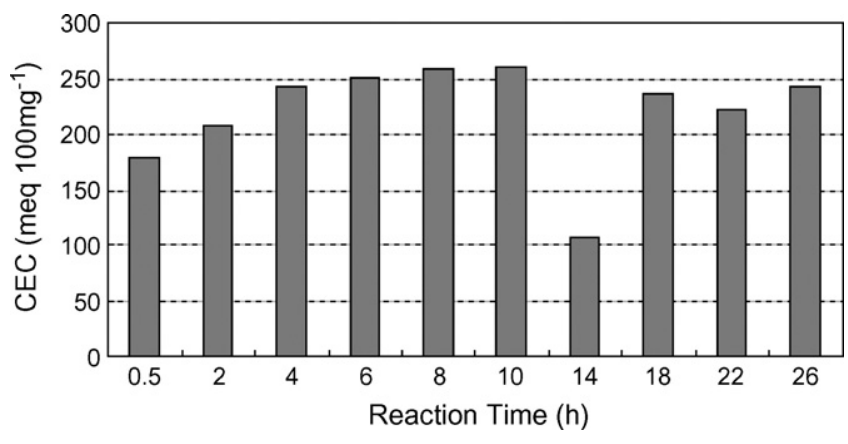

Fig. 6. Effect of reaction time on the CEC values of the synthesized products.

reached a plateau value at certain point. Comparatively, the dissolving rate of $\mathrm{Al}$ increased for a longer time at the early stage but decreased after reaching a maximum value [8]. Thus, the $\mathrm{SiO}_{2} / \mathrm{Al}_{2} \mathrm{O}_{3}$ ratio was $>2$ at the early stage (Table 1 ) to promote the formation zeolite $\mathrm{X}$, and then $\mathrm{Si}$ concentration became constant, while $\mathrm{Al}$ concentration still increased resulting in a lower $\mathrm{SiO}_{2} / \mathrm{Al}_{2} \mathrm{O}_{3}$ around $14 \mathrm{~h}$ to promote the formation zeolite $\mathrm{HS}$. With the decrease of $\mathrm{Al}$ concentration, the $\mathrm{Si} / \mathrm{Al}$ ratio increased again, which was favorable for zeolite $\mathrm{X}$ formation.

A similar effect of the hydrothermal reaction time on CEC is also found in Fig. 6. The CEC value reached $200 \mathrm{cmol} \mathrm{kg}^{-1}$ at $0.5 \mathrm{~h}$, indicating that the ash used in this study could form crystals within a short time.

\subsubsection{Morphological change}

Fig. 7 shows the SEM photographs of the raw material and MSWCA zeolite obtained at the optimum conditions. The raw ash (Fig. 7a) consists of irregular shaped particles and the surface is hollow and broken. Compared with the raw ash, MSWCA zeolite has marked changes in the surface morphology due to the alkali activation. Zeolite $\mathrm{X}$ deposites as fine octahedral crystals with size range of $0.5-1 \mu \mathrm{m}$ (Fig. 7b). Comparatively, spherical crystal particles of zeolite HS are general with larger size of 1-3 $\mu \mathrm{m}$ (Fig. 7c). The presence of large amount of regular crystal particles on the surface of product particles indicates high conversion of the raw ash into crystalline zeolites.

\subsubsection{Comparison of surface properties of MSWCA zeolite with CFA zeolite}

MSWCA zeolite has more advantages over CFA zeolite. Table 2 compares the surface properties of the two types of zeolites synthesized under the same conditions ( $\mathrm{NaOH} / \mathrm{ash}: 1.2$, temperature: $90^{\circ} \mathrm{C}$, time: $6 \mathrm{~h}$ ) in our laboratory. The surface area and pore diameter of MSWCA zeolite were more than twice those of CFA zeolite and, the CEC value of MSWCA zeolite was

Table 2

Comparison of surface properties of MSWCA zeolite and CFA zeolite

\begin{tabular}{lcc}
\hline & MSWCA zeolite & CFA zeolite \\
\hline Surface area $\left(\mathrm{m}^{2} \mathrm{~g}^{-1}\right)$ & 200 & 86 \\
Average pore diameter $(\AA)$ & 93.9 & 93.2 \\
Pore volume $\left(\mathrm{cm}^{3} \mathrm{~g}^{-1}\right)$ & 0.46 & 0.20 \\
CEC $\left(\mathrm{cmol} \mathrm{kg}^{-1}\right)$ & 249 & 177 \\
\hline
\end{tabular}
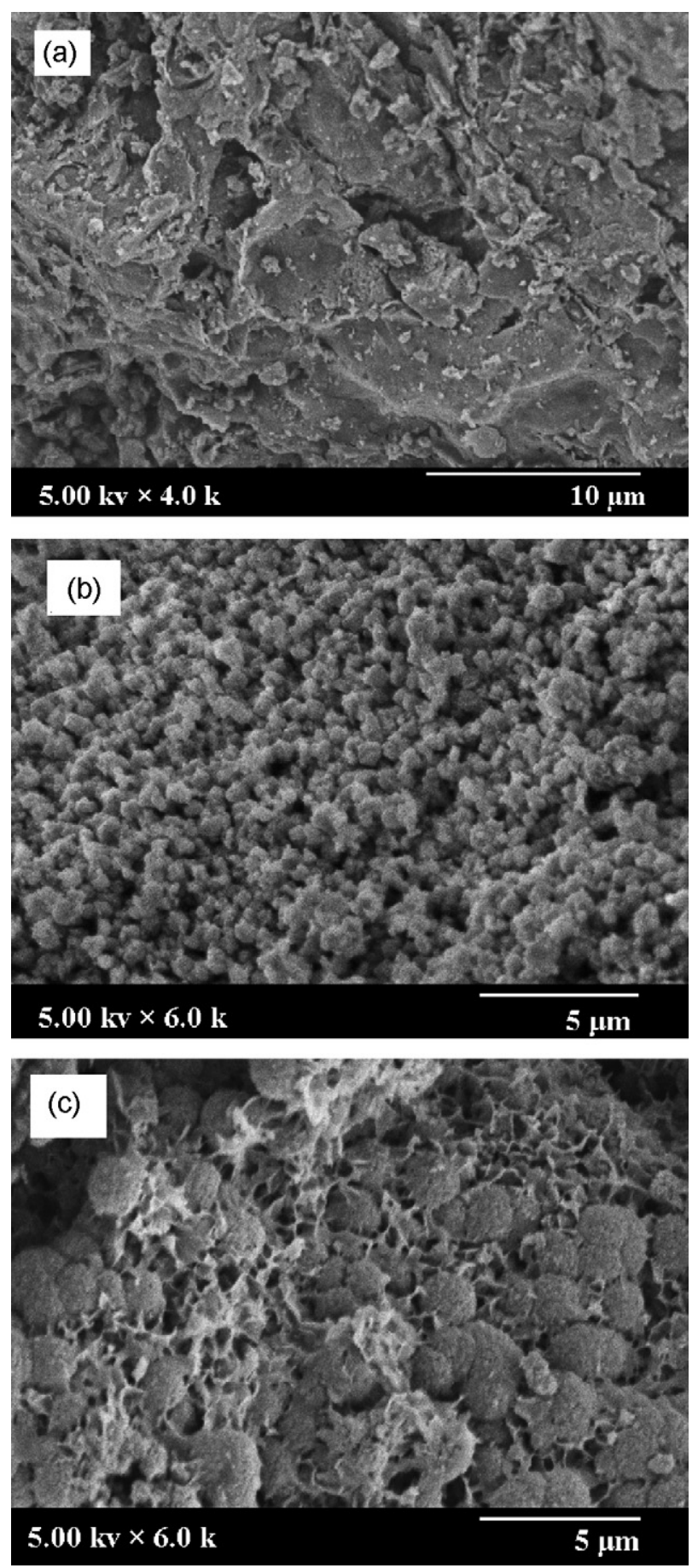

Fig. 7. SEM images of the synthesized products. (a) Raw ash; (b) zeolite X; (c) Zeolite HS.

1.41 times of that of CFA zeolite, which could be attributed to the high conversion rate of the raw ash into crystalline zeolite. The average pore diameter for the synthesized product was $93.9 \AA$, indicating that mesoporous material was developed. During the co-combustion of MSW with coal, the interaction between the two materials was a complex process, including re-distribution of various elements, decomposition and re-combination, causing the formation of Gismondine, Hematite and Anorthite, which contributed greatly to the high quality of MSWCA zeolite. 
Table 3

Langmuir and Freundlich parameters for $\mathrm{Zn}^{2+}$ adsorption

\begin{tabular}{|c|c|c|c|c|c|c|}
\hline & \multicolumn{3}{|l|}{ Langmuir } & \multicolumn{3}{|l|}{ Freundlich } \\
\hline & $Q_{\max }\left(\mathrm{mg} \mathrm{g}^{-1}\right)$ & $b\left(\mathrm{~L} \mathrm{mg}^{-1}\right)$ & $R^{2}$ & $\overline{K_{\mathrm{F}}\left(\mathrm{mg} \mathrm{g}^{-1}\right)}$ & $n$ & $R^{2}$ \\
\hline MSWCA zeolite & 121.97 & 0.7387 & 0.9966 & 84.18 & 11.99 & 0.9898 \\
\hline
\end{tabular}

\subsection{Application of MSWCA zeolite to wastewater treatment}

The ultimate goal of this work was to develop a new way for effective utilization of the abundant ash from MSW and coal co-combustion power plant. Therefore, the product synthesized in optimum conditions was applied for simulated $\mathrm{Zn}^{2+}$ contaminated wastewater treatment. Fig. 8 illustrates that the Langmuir isotherm model $\left(R^{2}=0.9966,0.9921\right.$ for MSWCA zeolite and CFA zeolite) could describe the isotherm better than the Freundlich isotherm model $\left(R^{2}=0.9898,0.9019\right)$.

The equilibrium adsorption data were tentatively fitted to Langmuir (Eq. (1)) and Freundlich (Eq. (2)) isotherms, which are two common functions for describing adsorption.

$\frac{C_{\mathrm{e}}}{q_{\mathrm{e}}}=\frac{C_{\mathrm{e}}}{Q_{\max }}+\frac{1}{b Q_{\max }}$

$\log q_{\mathrm{e}}=\log K_{\mathrm{F}}+\frac{1}{n} \log C_{\mathrm{e}}$

where $q_{\mathrm{e}}\left(\mathrm{mg} \mathrm{g}^{-1}\right)$ is the concentration of adsorbed metal ions per gram of adsorbent, $C_{\mathrm{e}}\left(\mathrm{mg} \mathrm{L}^{-1}\right)$ is the concentration of metal ion in equilibrium solution.

The constants of adsorption isotherms are calculated and given in Table 3. The Langmuir isotherm parameter $Q_{\max }$ $\left(\mathrm{mg} \mathrm{g}^{-1}\right)$ indicates the maximum adsorption capacity of adsorbent, while the parameter $b$ relates to the energy of adsorption. It can be seen in Table 3 that MSWCA zeolite presents larger adsorption capacity and bond energy $\left(121.97 \mathrm{mg} \mathrm{g}^{-1}\right.$ and $\left.0.7387 \mathrm{~L} \mathrm{mg}^{-1}\right)$ than CFA zeolite $\left(91.72 \mathrm{mg} \mathrm{g}^{-1}\right.$ and $\left.0.7387 \mathrm{~L} \mathrm{mg}^{-1}\right)$. On the other hand, the Parameter $K_{\mathrm{F}}\left(\mathrm{mg} \mathrm{g}^{-1}\right)$ and $n$ in Freundlich isotherm are the constants relate to the extent of the adsorption capacity and the degree of nonlinearity between solution concentration and adsorption, respectively. The $K_{\mathrm{F}}$ value of MSWCA zeolite is much higher than that of

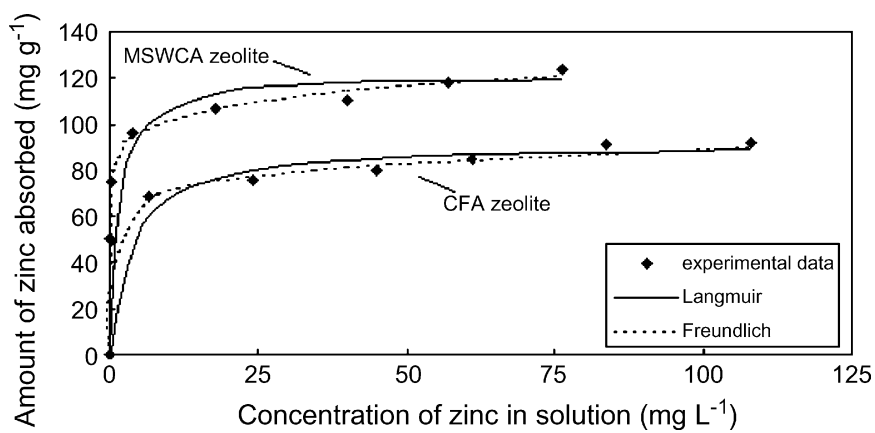

Fig. 8. Adsorption isotherms for $\mathrm{Zn}^{2+}$ onto MSWCA and CFA zeolites.
CFA zeolite, showing the superiority of MSWCA zeolite in the adsorption of zinc ion in low concentration range.

\section{Conclusions}

High quality zeolite products with maximum CEC value of $250 \mathrm{cmol} \mathrm{kg}^{-1}$ were successfully synthesized from MSW and coal co-combustion ash by fusion-hydrothermal process, demonstrating that this type of waste material is suitable for zeolite development. The properties of the zeolite products are mainly depended on $\mathrm{NaOH}$ concentration, reaction temperature and crystallization time. Lower $\mathrm{NaOH} /$ ash ratio and operating temperature is favorable for zeolites $\mathrm{X}$ development while higher $\mathrm{NaOH} /$ ash ratio and operating temperature is suitable for zeolite HS synthesis. Zeolite X exhibited a change of formation-decomposition-reformation along with the crystallization time. Compared to CFA zeolite, MSWCA zeolite developed in this study presented a higher surface area, higher pore volume, and a larger removal capacity for heavy metals from aqueous solution. The results of this work proposed a potential way for effective utilization of the special type of waste ash.

\section{Acknowledgements}

This study was financially supported by the National Basic Research Program of China with a funding number of 2007CB407303. The authors are grateful to Ms. Y.A. Feng in Zhengzhou Municipal Administration Bureau for her kindly cooperation in sample collection.

\section{References}

[1] L.B. Zhu, D. Sheng, Present situation of urban domestic waste in China and countermeasures, Environ. Sani. Eng. 14 (2006) 35-39 (in Chinese).

[2] B.K. Gullett, J.E. Dunn, K. Raghunathan, Effect of cofiring coal on formation of poly chlorinated dibenzo-p-dioxins and dibenzofurans during waste combustion, Environ. Sci. Technol. 34 (2000) 282-290.

[3] Z.P. Zhong, B.S. Jin, J.X. Lan, C.Q. Dong, H.C. Zhou, Dioxins emission and purification during co-combustion of municipal solid waste and coal mixture, Proc. CSEE 23 (2003) 184-188 (in Chinese).

[4] X.G. Jiang, X.P. Li, Y. Chi, J.H. Yan, Experimental study of emission of $\mathrm{HCl}$ on incinerating of typical MSW components and coal in fluidized bed, Proc. CSEE 24 (8) (2004) 210-214 (in Chinese).

[5] W.H. Jiao, Y.J. Na, M.H. Zheng, Q.G. Lu, Analysis of heavy metals in ash of co-firing of MSW and coal, J. Eng. Thermophys. 26 (2005) 347-350 (in Chinese).

[6] X.J. Bao, J.J. Cai, H.Q. Liu, Q. Zhang, W. Fu, Experimental study on pyrolysis characteristics of urban refuse blending with coal, J. Eng. Thermophys. 25 (2004) 691-694 (in Chinese). 
[7] J.H. Hu, H. Wang, F. He, G.R. Bao, W.H. Ma, Melting characteristics and compounds analysis of slag from mixed combustion of MSW with coal, Acta Sci. Circumst. 23 (2003) 540-545 (in Chinese).

[8] N. Murayama, H. Yamamoto, J. Shibata, Mechanism of zeolite synthesis from coal fly ash by alkali hydrothermal reaction, Inter. J. Miner. Process. 64 (2002) 1-17.

[9] A. Molina, C. Poole, A comparative study using two methods to produce zeolites from fly ash, Mineral. Eng. 17 (2004) 167-173.

[10] G.C.C. Yang, T.Y. Yang, Synthesis of zeolite from municipal incinerator fly ash, J. Hazard. Mater. 62 (1998) 75-89.

[11] S.M.D. Bosco, R.S. Jimenez, W.A. Carvalho, Removal of toxic metals from wastewater by Brazilian natural scolecite, J. Colloid Inter. Sci. 281 (2005) 424-431.

[12] D.M.A. Melo, J.R. de Souza, M.A.F. Melo, A.E. Martinelli, G.H.B. Cachima, J.D. Cunha, Evaluation of the zinox and zeolite materials as adsorbents to remove $\mathrm{H}_{2} \mathrm{~S}$ from natural gas, Colloid Surf. A 272 (2006) $32-36$.
[13] A.E. Osmanlioglu, Treatment of radioactive liquid waste by sorption on natural zeolite in Turkey, J. Hazard. Mater. 137 (2006) 332-335.

[14] J. Scott, D. Guang, K. Naeramitmarnsuk, M. Thabuot, R. Amal, Zeolite synthesis from coal fly ash for the removal of lead ions from aqueous solution, J. Chem. Technol. Biotechnol. 77 (2001) 63-69.

[15] B. Bonelli, L. Forni, A. Aloise, J.B. Nagy, G. Fornasari, E. Garrone, A. Gedeon, G. Giordano, F. Trifirò, Beckman rearrangement reaction: about the role of defect groups in high silica zeolite catalysts, Micropor. Mesopor. Mater. 101 (2006) 153-160.

[16] X. Querol, A. Alastuey, F. Plana, L.A. Soler, Synthesis of Na-zeolites from fly ash, Fuel 76 (1997) 793-799.

[17] R. Juan, S. Hernández, J.M. Andrés, C. Ruiz, Synthesis of granular zeolitic materials with high cation exchange capacity from agglomerated coal fly ash, Fuel 86 (2007) 1811-1821.

[18] M. Inada, Y. Eguchi, N. Enomoto, J. Hojo, Synthesis of zeolite from coal fly ashes with different silica-alumina composition, Fuel 84 (2005) 299304. 